\title{
LOS MOVIMIENTOS ECLESIALES Y LAS NUEVAS COMUNIDADES: ENTRE INSTITUCIÓN Y CARISMA ${ }^{1}$
}

\author{
Ecclesial Movements And New Communities: Between institution and charism
}

\author{
Miguel Delgado Galindo ${ }^{2}$
}

\section{Resumen}

Los movimientos eclesiales y las nuevas comunidades son realidades eclesiales portadoras de carismas que el Espíritu Santo distribuye para el bien común de la Iglesia, con el fin de contribuir a la santidad no solo de un conjunto determinado de fieles, sino de todos los miembros del Pueblo de Dios. Los movimientos eclesiales y las nuevas comunidades, integrados mayoritariamente por fieles laicos, encuentran su origen en la eclesiología de comunión que caracteriza el magisterio del Concilio Vaticano II, y constituyen un motivo de esperanza para la evangelización en este periodo de la historia. La profundización de la eclesiología del último concilio ecuménico ha puesto de manifiesto la coesencialidad entre los dones jerárquicos y carismáticos en la constitución divina de la Iglesia, aspecto que ha sido elevado a la categoría de principio teológico. Los últimos papas han expresado su estima hacia estas nuevas realidades eclesiales, han establecido criterios para su discernimiento, han dado indicaciones generales para facilitar su armónica inserción en las iglesias particulares donde se encuentran presentes sus miembros y han contribuido al proceso de conversión misionera en la que está comprometida la Iglesia entera.

Palabras clave: Movimientos eclesiales; Nuevas comunidades; Institución; Carisma; Coesencialidad; Sinodalidad.

1 Conferencia pronunciada durante la CVI Asamblea Plenaria del Episcopado Colombiano (Bogotá, 2-7 de julio de 2018), con el tema "Movimientos eclesiales y nuevas comunidades: Signo de la fecundidad del Espíritu en la vida de la Iglesia”.

2 Doctorado en Derecho canónico por la Pontificia Universidad de la Santa Cruz de Roma, Italia. Exsubsecretario del Consejo Pontificio para los Laicos. Correo electrónico: miqueldg63@gmail.com 


\section{Abstract}

The ecclesial movements and new communities are ecclesial realities bearing charisms that the Holy Spirit gives for the common good of the Church, in order to contribute to the holiness not only of a specific group of the faithful, but of all the members of the people of God. The ecclesial movements and new communities, most of whose members are lay faithful, find their origins in the ecclesiology of communion that characterises the magisterium of the Second Vatican Council, and are a reason for hope in the evangelisation of our times. Deeper reflection on the last ecumenical council's ecclesiology has brought to light the co-essentiality of hierarchical and charismatic gifts in the Church's divine constitution, an aspect that has been elevated to the category of theological principle. Recent Popes have expressed their esteem for these new ecclesial realities, establishing criteria for discernment and giving general indications to facilitate their harmonious integration in the Particular Churches where their members are found, contributing to the process of missionary conversion in which the whole Church is engaged.

Keywords: Ecclesial movements; New Communities; Institution; Charism; Co-essentiality; Synodality.

\section{El principio de coesencialidad entre dones jerárquicos y carismáticos}

El 30 de mayo de 2018, se cumplieron veinte años de la memorable vigilia de Pentecostés del papa san Juan Pablo II con los movimientos eclesiales y las nuevas comunidades ${ }^{3}$ en la Plaza de San Pedro en el Vaticano (Delgado, 2013). La Iglesia entera vivió en 1998 un año especial dedicado al Espíritu Santo (Juan Pablo II, 1994, n. ${ }^{\circ} 44-48$ ), en preparación del gran Jubileo de 2000, que fue precedido por un año dedicado a Jesucristo (1997) y seguido de otro centrado en Dios Padre (1999). Encuentros análogos con estas nuevas realidades eclesiales han tenido lugar con Benedicto XVI (2006) y con el papa Francisco, con ocasión del Año de la Fe (2013). Los últimos pontífices concuerdan en considerar a los movimientos eclesiales y las nuevas comunidades como válidos instrumentos para la formación cristiana de los fieles laicos y ambientes propicios desde donde se contribuye a la nueva evangelización del mundo, misión a la cual está convocado todo el Pueblo de Dios.

Volviendo a 1998, en el mensaje de Juan Pablo II del 27 de mayo, enviado a los participantes al I Congreso Mundial de los Movimientos Eclesiales, organizado por el Consejo Pontificio para los Laicos (27-29 de mayo de 1998), el papa definió los aspectos institucional y carismático como co-essenziali en la constitución divina de la Iglesia fundada por Jesucristo. Se trataba de una expresión novedosa, que hasta entonces no había sido utilizada por el magisterio pontificio, circunstancia que provocó una notable

3 Movimientos eclesiales y nuevas comunidades son expresiones sinónimas que pueden ser utilizadas indistintamente. Entre las nuevas comunidades, se pueden incluir las realidades eclesiales asociativas surgidas en el ámbito de la corriente ecuménica de gracia que constituye la Renovación Carismática Católica, así como las comunidades del Camino Neocatecumenal. Por razones de economía lingüística, utilizo aquí solo la expresión "movimientos eclesiales". 
disparidad en la traducción a las diversas lenguas (Coda, 2018, pp. 33-43). En español, el término coessenziali del mensaje se tradujo por "esenciales" (Juan Pablo II, 1998, n. ${ }^{\circ} 23$ ). En cambio, en el discurso pronunciado el 30 de mayo de 1998 en la Plaza de San Pedro, el papa utilizó la expresión quasi co-essenziali, "casi coesenciales" (p. 14). Como se puede apreciar, la diferencia de significados es notable. Se entiende que la carga de novedad que representaba la locución "coesencialidad" dificultara los trabajos de elaboración de los textos y su posterior traducción. De ahí que no se pueda afirmar a ciencia cierta que se tratara de un error material o, más bien, del llamado "yerro del entendido", es decir, la equivocación de una persona conocedora de la materia, y que, por consiguiente, es de mayor trascendencia. Sea cual fuese la razón de estas discordancias en las traducciones de la palabra coesencialidad, este hecho motivó que la relación entre institución y carismas suscitara un renovado interés en el ámbito eclesiológico. El 15 de mayo de 2016, la Congregación para la Doctrina de la Fe publicó la carta Iuvenescit Ecclesia, sobre la relación entre dones jerárquicos y carismáticos para la vida y la misión de la Iglesia. Este documento constituye, sin duda, un nuevo acto de recepción de la eclesiología de comunión que caracteriza el entero magisterio del Concilio Vaticano II (Ratzinger, 2015, pp. 539-561).

Sobre este aspecto cabe subrayar que los movimientos eclesiales han contribuido, cada uno según su proprio carisma, a implementar la eclesiología de comunión, ya sea entendida como la participación de nuestra humanidad en el misterio de la vida trinitaria del Padre, del Hijo y del espíritu Santo (dimensión vertical), ya sea considerada la unión entre todos los creyentes en vista del fin último de la Iglesia, que no es otro que la salvación de las almas (dimensión horizontal). La Iglesia es una comunión de mutuas ayudas sobrenaturales. Dentro de ella encontramos una pluralidad de carismas y vocaciones, ordenadas hacia un mismo fin, y bajo la guía de una misma jerarquía, en cuyo ápice se encuentra el Romano Pontífice, en quien reside el principio de unidad de fe y comunión en la Iglesia. El redescubrimiento de los sacramentos de la iniciación cristiana (bautismo, confirmación y eucaristía) como medios a través de los cuales se accede a la comunión en la Iglesia ha sido esencial a este fin.

La carta Iuvenescit Ecclesia pone de manifiesto el fundamento trinitario de la coesencialidad entre los dones jerárquicos, fruto del sacramento del orden sacerdotal, de los que están dotados los pastores de la Iglesia, y los dones carismáticos, que pueden recibir todos los fieles bautizados para el bien de todo el cuerpo eclesial; ambos dones, jerárquicos y carismáticos, contemplados a la luz de los designios del Padre, que se realiza en las misiones del Hijo y del Espíritu Santo. Esta carta de la Congregación para la Doctrina de la Fe ofrece una importante contribución a una ordenada comunión entre los dones jerárquicos y carismáticos, en vista de una renovación del impulso evangelizador del Pueblo de Dios, y de la conversión pastoral a la que nos llama el papa Francisco (Francisco, 2013, n. ${ }^{\circ} 25-33$ ).

Con posterioridad a la carta Iuvenescit Ecclesia, la Comisión Teológica Internacional, en el documento que lleva por título "La sinodalidad en la vida y en la misión de la Iglesia" (2 de marzo de 2018), considera la coesencialidad entre dones jerárquicos y carismáticos como un verdadero principio eclesiológico que debe ser valorado según las enseñanzas del Concilio Vaticano II. La aplicación de este principio supone la participación en la vida de la Iglesia de las comunidades de vida consagrada, de los movimientos y de las nuevas comunidades eclesiales. El documento citado menciona que todas estas realidades, surgidas del impulso dado por el Espíritu Santo para la renovación de la Iglesia, pueden ofrecer experiencias significativas de articulación sinodal de la vida de comunión eclesial y estímulo para encontrar nuevos caminos de 
evangelización. Algunas de estas realidades eclesiales constituyen ejemplos de integración entre las diversas vocaciones en la Iglesia, en la perspectiva de la eclesiología de comunión (n. ${ }^{\circ} 74$ ).

Leemos en el Catecismo de la Iglesia Católica: "Extraordinarios o sencillos y humildes, los carismas son gracias del Espíritu Santo, que tienen directa o indirectamente una utilidad eclesial; los carismas están ordenados a la edificación de la Iglesia, al bien de los hombres y a las necesidades del mundo" (n. ${ }^{\circ} 799$ ). Un carisma, por tanto, es una gracia especial (gratia gratis data) diversa de la gracia santificante (gratia gratum faciens), que el Espíritu Santo derrama no solo para la santificación de un fiel, sino para el bien de toda la comunidad eclesial (Pellitero, 2003, pp. 535-551; santo Tomás de Aquino, Summa theologiae, I-II, q. III, 4; 3, 7, 7). Es destacar que santo Tomás de Aquino no utiliza el término "carisma”, y como equivalente usa la expresión gratia gratis data, que es la gracia mediante la cual un hombre ayuda a otro a volver a Dios. Esta gracia no se concede para la santificación de la persona que la recibe, sino para cooperar en la santificación ajena (santo Tomás de Aquino, Summa theologiae, I-II, q. 111, a. 1, resp.).

\section{¿Qué es un movimiento eclesial?}

Es necesario reconocer que no resulta una tarea sencilla definir con precisión la expresión "movimiento eclesial". La gran mayoría de los movimientos eclesiales (me refiero a todas aquellas realidades eclesiales que en nuestros tiempos son identificadas con esta denominación) han surgido a lo largo de la segunda mitad del siglo XX, y han tomado un gran impulso a partir del Concilio Vaticano II. Muchos han nacido durante el pontificado de san Juan Pablo II, quien definió este proceso como "una nueva época asociativa de los fieles laicos" (Juan Pablo II, 1988, n. ${ }^{\circ} 29$ ).

No obstante las dificultades que encontramos a la hora de intentar definir una expresión como es la de movimiento eclesial, podemos individuar algunos rasgos característicos que la describen. En general, el término movimiento indica un conjunto de tendencias de diversa naturaleza (religiosa, política, social, estética, etc.), caracterizadas por la fluidez y el dinamismo, teniendo en sí mismas una fuerte carga innovadora. Así define el término movimiento el Diccionario de la lengua española de la Real Academia Espańola (RAE, 2014), citando como ejemplos el movimiento de Oxford (reforma espiritual y teológica de la Comunión Anglicana, que desde 1833 tuvo como principal protagonista al cardenal John H. Newman), el movimiento socialista (creación de las condiciones necesarias para hacer posible la sustitución de los fundamentos sociales y económicos del capitalismo y abrir el paso a una sociedad socialista, que en siglo XIX tuvo como principales exponentes a Karl Marx y Friedrich Engels) y el movimiento romántico (corriente artística también del siglo XIX que primaba el desarrollo de los sentimientos y del individualismo sobre la razón y la voluntad, encontrando su inspiración en el pasado y, específicamente, en la Edad Media).

Más concretamente, la palabra movimiento ha sido muchas veces empleada en el ámbito eclesial para designar acontecimientos nuevos que han atravesado la historia de la Iglesia: el monaquismo, la reforma benedictina cluniacense, las órdenes mendicantes, etc. (Ratzinger, 2015, pp. 341-348), como también expresiones de renovación teológica en continuidad con la tradición: el movimiento litúrgico (redescubrimiento de la riqueza espiritual de la liturgia cristiana primitiva y del principio sacramental de la Iglesia, que contó con las aportaciones de Romano Guardini y de Odo Casel), el movimiento bíblico (conocimiento más profundo de la palabra de Dios, manifestado en los estudios exegéticos publicados 
durante la primera mitad del siglo XX), el movimiento ecuménico (restablecimiento de la unidad entre todos los cristianos, que fue uno de los principales objetivos del Concilio Vaticano II), por citar solo algunos. En relación con este tema, el cardenal Ratzinger puntualizó que, más que como movimientos, deberían identificarse como corrientes que con el transcurso del tiempo han podido desembocar en movimientos concretos (p. 351).

La reflexión eclesiológica realizada con motivo del Concilio Vaticano II ha supuesto la introducción de una nueva acepción de la palabra movimiento todavía no incorporada en el Diccionario de la RAE. Este término, en efecto, es hoy empleado también para designar determinadas realidades eclesiales, que constituyen expresiones del Pueblo de Dios y poseen una subjetividad propia, y que han contribuido a la renovación de la vida de la Iglesia a partir del siglo XX.

En el mensaje dirigido a los participantes al I Congreso Mundial de los Movimientos Eclesiales, que se celebró en Roma del 27 al 29 de mayo de 1998, san Juan Pablo II escribió:

¿Qué se entiende, hoy, por Movimiento? El término es a menudo referido a realidades distintas entre sí, a veces, hasta por su configuración canónica. $\mathrm{Si}$, por una parte, esta no puede ciertamente agotar ni fijar la riqueza de las formas suscitadas por la creatividad vivificante del Espíritu de Cristo, por otra indica una realidad eclesial concreta en la que participan principalmente laicos, un itinerario de fe y de testimonio cristiano que basa su método pedagógico en un carisma preciso otorgado a la persona del fundador en circunstancias y modos determinados. (Juan Pablo II, 1998, n. ${ }^{\circ}$ 23)

En estas palabras del papa Juan Pablo II, podemos encontrar los elementos esenciales para la definición de un movimiento eclesial. En primer lugar, se trata de una realidad concreta en la Iglesia, compuesta mayoritariamente por fieles laicos. Los movimientos eclesiales son, por tanto, una realidad eminentemente laical, no obstante puedan pertenecer a ellos también clérigos y miembros de institutos de vida consagrada y sociedades de vida apostólica. La gran mayoría de los movimientos eclesiales han sido configurados canónicamente hasta ahora como asociaciones de fieles y, por tanto, internacionalmente entran en el ámbito de competencia del actual Dicasterio para los laicos, la familia y la vida.

Un movimiento eclesial se funda sobre un carisma originario recibido por un fundador en unas circunstancias históricas determinadas. Se trata de un carisma vocacional, que estimulan al fiel cristiano a asumir compromisos de vida que abrazan la entera existencia, y lo impulsan a una donación personal a Dios.

Por otra parte, los movimientos eclesiales son portadores de una pedagogía propia de la fe que conduce a sus miembros a un encuentro personal con Cristo y, al mismo tiempo, los alienta a evangelizar.

Ofreciendo una definición de movimiento eclesial, el entonces cardenal Joseph Ratzinger afirmaba que "los movimientos provienen en su mayoría de una personalidad carismática, se configuran en forma de comunidades concretas que, a partir de ese origen, viven con nuevo espíritu todo el Evangelio y reconocen sin titubeos a la Iglesia como su fundamento, sin la cual no podrían existir" (Ratzinger, 2015, pp. 351, 354-387).

A la luz de lo dicho hasta ahora, los movimientos eclesiales se presentan a nuestros ojos como realidades asociativas de origen carismático, fundamentalmente laicales, estructuradas como comunidades de fieles, 
con un método pedagógico propio de la fe, que conlleva para sus miembros un compromiso existencial en vista de la realización de la vocación cristiana, y están dotados de dinamismo apostólico.

\section{Los tres últimos papas y los movimientos eclesiales}

San Juan Pablo II tuvo ocasión de calificar a los movimientos eclesiales de dones ofrecidos por el Espíritu Santo y motivo de esperanza para la Iglesia y la humanidad entera. El papa Wojtyła supo acogerlos y valorarlos; los propuso a todos los obispos y los invitó a difundirse en las Iglesias particulares con humildad y sentido de comunión. ¿Cuál es la razón profunda de esta actitud? La respuesta se puede encontrar en las palabras del mismo pontífice dirigidas a los participantes en el inolvidable encuentro con los movimientos eclesiales, que tuvo lugar la tarde del 30 de mayo de 1998, vigilia de Pentecostés, en la Plaza de San Pedro:

En nuestro mundo, especialmente dominado por una cultura secularizada que fomenta y propone modelos de vida sin Dios, la fe de muchos es puesta a dura prueba y muchas veces, sofocada y apagada. Se advierte, entonces, con urgencia, la necesidad de un anuncio fuerte y de una sólida y profunda formación cristiana. ¡Cuánta necesidad existe hoy de personalidades cristianas maduras, conscientes de la propia identidad bautismal, de su propia vocación y misión en la Iglesia y en el mundo! ¡Cuánta necesidad de comunidades cristianas vivas! Y aquí aparecen, entonces, los movimientos y las nuevas comunidades eclesiales: ellos son la respuesta suscitada por el Espíritu Santo a este dramático desafío de fin de milenio. Ustedes son esta respuesta providencial. (Juan Pablo II, 1998, n.o 23, p. 14)

Unido idealmente al evento de san Juan Pablo II en 1998, podemos también recordar el encuentro de Benedicto XVI con los movimientos eclesiales y las nuevas comunidades que se celebró en la Plaza de San Pedro el 3 de junio de 2006, durante la celebración de las primeras vísperas de la solemnidad de Pentecostés. Estas son las directrices que Benedicto XVI hizo presentes a los participantes en su homilía:

Los movimientos han nacido de la sed de una vida verdadera [...]. Los movimientos eclesiales quieren y deben ser escuelas de libertad [...]. ¡Forman parte de la edificación del único cuerpo! [...]. Ustedes no cesarán de llevar sus dones a la comunidad entera [...]. Queridos amigos, les pido que sean, todavía más, mucho más, colaboradores del ministerio apostólico universal del Papa, abriendo las puertas a Cristo. (Benedicto XVI, 2006, n.o 23)

Con ocasión del II Congreso Mundial de los Movimientos Eclesiales que precedió a este encuentro, Benedicto XVI dirigió a los miembros de los movimientos eclesiales y a las nuevas comunidades un mensaje (22 de mayo de 2006) en el cual se lee: "Ustedes pertenecen a la estructura viva de la Iglesia" (Benedicto XVI, 2006, n.o 23).

El papa Francisco conoce también de cerca estas realidades eclesiales y las considera una riqueza para la Iglesia, a la vez que ha advertido sobre posibles dificultades (Francisco, 2018, n. ${ }^{\circ}$ 58). Siendo pastor diocesano a Buenos Aires, una de las últimas tareas que había recibido el cardenal Jorge Mario Bergoglio

en el seno de la Conferencia Episcopal Argentina fue la de asistente espiritual de la Renovación Carismática Católica. 
Un encuentro con movimientos eclesiales y nuevas comunidades similar a los celebrados con san Juan Pablo II y Benedicto XVI tuvo lugar también con el papa Francisco el 18 de mayo de 2013. El papa respondió a cuatro preguntas que le fueron formuladas. Preguntado acerca de lo más importante a lo que tenían que tender los movimientos, las asociaciones y las comunidades para llevar a cabo la misión a la que están llamados, Francisco respondió que en primer lugar, estaba Jesús y dejarse guiar por Él: la organización, las estrategias son cuestiones secundarias. Después de Jesús, la oración: dejarse mirar por el Señor desde el sagrario. "Somos verdaderos evangelizadores dejándonos guiar por Él [...] nuestro leader es Jesús". Y, en tercer lugar, el testimonio. "No con nuestras ideas, sino con el Evangelio vivido en la propia existencia y que el Espíritu Santo hace vivir dentro de nosotros". Francisco se refirió también a una Iglesia que sale, que va a las periferias de la existencia humana. Decía:

No os encerréis, por favor. Esto es un peligro: nos encerramos en la parroquia, con los amigos, en el movimiento, con quienes pensamos las mismas cosas... pero ¿̇sabéis qué ocurre? Cuando la Iglesia se cierra, se enferma, se enferma. Pensad en una habitación cerrada durante un ańo; cuando vas huele a humedad, muchas cosas no marchan. Una Iglesia cerrada es lo mismo: es una Iglesia enferma. La Iglesia debe salir de sí misma. ¿Adónde? Hacia las periferias existenciales, cualesquiera que sean. Pero salir. Jesús nos dice: "Id por todo el mundo. Id. Predicad. Dad testimonio del Evangelio" (cf. Mc 16, 15). (Francisco, 2013, n. ${ }^{\circ} 21$ )

Al día siguiente, 19 de mayo de 2013, en la homilía de la santa misa de la solemnidad de Pentecostés, el papa Francisco mencionó tres palabras relacionadas con la acción del Espíritu Santo: novedad, armonía y misión. Dios trae a nuestra vida la novedad que nos realiza, que nos da la verdadera alegría, la verdadera serenidad. El papa nos anima a permanecer abiertos a las sorpresas de Dios, a no cerrarnos en nuestras seguridades, en nuestros gustos personales. En la Iglesia, siguió diciendo Francisco, el Espíritu Santo hace la armonía. El Paráclito armoniza la diversidad de carismas y de dones que, bajo su acción, constituyen una gran riqueza para la Iglesia. El Espíritu Santo es espíritu de unidad, pero de una unidad que no es uniformidad. Citando a un padre de la Iglesia, Francisco recordaba que el Espíritu Santo ipse harmonia est (Él mismo es armonía). Solo el Espíritu Santo "puede suscitar la diversidad, la pluralidad, la multiplicidad y, al mismo tiempo, realizar la unidad" (Francisco, 2013, n. ${ }^{\circ} 21$ ). El aforismo ipse harmonia est, referido al Espíritu Santo, citado en varias ocasiones por Francisco, se atribuye a san Basilio Magno (De Spiritu Sancto, XVI, 38: PG 32, 139-140).

La novedad y la armonía conducen a la misión. El Espíritu Santo nos impulsa a anunciar la vida de Jesucristo, la alegría de la fe, a no quedarnos encerrados en nosotros mismos, en nuestros propios recintos, en nuestra autorreferencialidad. Francisco utiliza una bella metáfora para hablarnos de la acción del Espíritu Santo: el alma es como una barca de vela, el Espíritu Santo es el viento que sopla en la vela para que la barca navegue y los impulsos del viento son los dones del Espíritu Santo.

Otro momento significativo de la relación del papa Francisco con las nuevas realidades asociativas laicales de la Iglesia fue la audiencia concedida el 22 de noviembre de 2014 a los participantes al III Congreso Mundial de los Movimientos Eclesiales y las Nuevas Comunidades (Roma, 20-22 de noviembre de 2014), que tuvo como tema "La alegría del Evangelio: una alegría misionera" (Francisco, 2014, n. ${ }^{0} 48$ ).

En sus palabras, el papa subrayó que la conversión y la misión son dos elementos esenciales de la vida cristiana que están estrechamente relacionados entre sí. Sin una verdadera conversión del corazón y de la 
mente a Dios, no se puede anunciar el Evangelio; pero sin una apertura permanente a la misión no se da la conversión, y la fe se hace estéril.

Francisco animó a conservar la lozanía del carisma propio de cada realidad eclesial, renovando siempre "el primer amor" (Ap 2, 4). Es preciso volver siempre a las fuentes del carisma, con la disposición a responder siempre a la llamada del Señor, y huir de la tentación de encerrar el Espíritu en estructuras externas.

Un segundo aspecto analizado por el papa fue el respeto de la libertad en el proceso de acogida y acompańamiento paciente de las personas, respetando sus tiempos y esperando que cada una madure con la acción del Señor en sus almas.

La última cuestión tratada es la comunión, como sello más importante del Espíritu Santo, que supone la comunión de cada movimiento y comunidad eclesial en la comunión superior de la Iglesia jerárquica, así como la superación de las rivalidades y divisiones. Para Francisco, la comunión consiste también en afrontar unidos los temas más importantes, y mencionó la vida, la familia, la paz, la lucha contra la pobreza en todas sus formas, la libertad religiosa y de educación.

\section{Criterios de eclesialidad para los movimientos eclesiales}

El reconocimiento de los movimientos eclesiales por la autoridad de la Iglesia requiere la existencia de criterios claros y precisos de discernimiento eclesial. Son los llamados criterios de eclesialidad, contenidos en la exhortación apostólica post-sinodal Christifideles laici, de san Juan Pablo II, en el n. ${ }^{\circ}$ 30:

10) La primacía de la vocación cristiana a la santidad. Las asociaciones de fieles están llamadas a ser instrumento de santidad en la Iglesia, vocación que todos los cristianos han recibido con el sacramento del Bautismo.

$2^{\circ}$ ) La responsabilidad de confesar la fe católica, acogiendo y proclamando la verdad sobre la Iglesia y sobre el hombre, en obediencia al Magisterio de la Iglesia, que la interpreta auténticamente.

$3^{\circ}$ ) El testimonio de una comunión firme y convencida con el Romano Pontífice y con los Obispos, que se manifiesta en la disponibilidad para acoger sus enseñanzas doctrinales y sus orientaciones pastorales, y exige el reconocimiento de la legítima pluralidad de formas asociativas en la Iglesia, así como la disponibilidad para la colaboración.

4º) La conformidad y la participación en el fin apostólico de la Iglesia, es decir, la santificación de los hombres y la evangelización.

5o) El compromiso de una presencia en la sociedad humana, con el fin de crear unas condiciones más justas y fraternas en la sociedad. 
La carta Iuvenescit Ecclesia, de la Congregación para la Doctrina de la Fe, hace también referencia a los criterios para el discernimiento de los dones carismáticos. De los ocho criterios que menciona el n. ${ }^{\circ}$ 18 del documento, seis son claramente reconducibles a los mencionados en la exhortación apostólica Christifideles laici, de san Juan Pablo II. En cambio, supone una novedad que sean considerados criterios de eclesialidad para este discernimiento el reconocimiento y la estima de la recíproca complementariedad de otros componentes carismáticos en la Iglesia, así como la aceptación de los momentos de prueba en el discernimiento de los carismas.

\section{Iglesias particulares y movimientos eclesiales}

La relación entre las Iglesias particulares y los movimientos eclesiales es una importante cuestión eclesiológica. Los movimientos eclesiales constituyen un reflejo de la dimensión universal y, al mismo tiempo, particular de la Iglesia. La mutua interioridad que existe entre las dos dimensiones de la Iglesia: universal y particular, puede ser descrita como la presencia del todo (Iglesia universal) en la parte (Iglesia particular), siendo esta última parte del todo.

Si estudiamos la historia de los movimientos eclesiales, comprobamos que todos ellos han surgido de una experiencia carismática en una determinada Iglesia particular. Sin embargo, por su misma esencia, los movimientos eclesiales están llamados a extenderse a otras Iglesias particulares, como consecuencia del espíritu evangelizador que anima a sus miembros, que es una clara manifestación de la apostolicidad de la Iglesia. Los movimientos eclesiales son realidades eclesiales que ponen de manifiesto la dimensión universal de su misión, se hacen presentes en las Iglesias particulares y desarrollan una acción eclesial interdiocesana. Después de haber obtenido uno o varios reconocimientos diocesanos, con el transcurso de los ańos los fundadores de los movimientos eclesiales se dirigen a la Sede Apostólica para solicitar el reconocimiento internacional.

Esta característica común de los movimientos eclesiales ha podido motivar en el pasado algunas dificultades con la autoridad eclesiástica. Sobre este particular, cabe decir que la Iglesia ha conocido en su historia situaciones de este tipo que han coincidido con etapas de gran renovación misionera. Basta pensar en la controversia surgida en el seno de la Universidad de París en los siglos XIII-XIV, que tuvo como protagonistas a teólogos de órdenes mendicantes (santo Tomás de Aquino y san Buenaventura) y maestros del clero secular (Juan de Pouilly y Tomás de Bailly). Buena parte de este debate se centró en la organización diocesana y parroquial respecto del privilegio pontificio que permitía a las órdenes mendicantes predicar y confesar libremente por toda Europa (Congar, 1961, pp. 35-151; Álvarez de las Asturias, 2017, pp. 189-211; Ratzinger, 2013, pp. 591-619; Viana, 2002, pp. 49-85).

Carisma e institución se armonizan en la noción de comunión. La communio, en este caso entendida como communio fidelium, es decir, la unión de todos los bautizados en orden a la consecución del fin último de la Iglesia, se encuentra en la base de las relaciones eclesiales y constituye el criterio hermenéutico para

una adecuada relación entre unidad y pluriformidad en la Iglesia, aspectos constitutivos de la comunión eclesial (Sínodo de los Obispos, 1985, Enchiridion Vaticanum, vol. 9, n.o 1801). 
La comunión no es una noción teológica abstracta, ni mucho menos un lugar común, ${ }^{4}$ sino que encuentra aplicaciones concretas en la vida de la Iglesia. En la carta Communionis notio (28 de mayo de 1992), sobre algunos aspectos de la Iglesia considerada como comunión, de la Congregación para la Doctrina de la Fe, se puede leer:

Para una visión más completa de este aspecto de la comunión eclesial —unidad en la diversidad—, es necesario considerar que existen instituciones y comunidades establecidas por la Autoridad Apostólica para peculiares tareas pastorales. Estas, en cuanto tales, pertenecen a la Iglesia universal, aunque sus miembros son también miembros de las Iglesias particulares donde viven y trabajan. Tal pertenencia a las Iglesias particulares, con la flexibilidad que le es propia, tiene diversas expresiones jurídicas. Esto no solo no lesiona la unidad de la Iglesia particular fundada en el Obispo, sino que por el contrario contribuye a dar a esta unidad la interior diversificación propia de la comunión. (n. 16)

Los movimientos eclesiales no pueden ser considerados como realidades "forasteras" en la Iglesia particular, precisamente porque sus miembros son fieles de la Iglesia particular, donde viven y actúan. Esta visión denotaría una idea estrecha y empobrecida de la Iglesia en su conjunto, porque carecería de una propiedad de la Iglesia, como es la catolicidad. En cuanto formas de expresión de los carismas, los movimientos eclesiales actualizan el misterio de la Iglesia en la Iglesia particular donde viven y actúan sus miembros y constituyen "elementos al servicio de la comunión entre las diversas Iglesias particulares" (Congregación para la Doctrina de la Fe, 1992, n. ${ }^{\circ}$ 16, in fine).

En la carta apostólica Novo millennio ineunte (6 de enero de 2001), Juan Pablo II precisa que reviste gran importancia para la comunión "promover las diversas realidades de asociación, que tanto en sus modalidades más tradicionales como en las más nuevas de los movimientos eclesiales, siguen dando a la Iglesia una viveza que es don de Dios y constituye una auténtica primavera del Espíritu” (n. 46).

La comunión comporta, evidentemente, la unidad en torno al obispo, a quien corresponde el discernimiento y el acompañamiento pastoral de los carismas, así como la coordinación de las diversas formas de apostolado en la Iglesia particular (Pablo, 1965 n. ${ }^{0}$ 17). Los movimientos eclesiales, de acuerdo con su carisma propio, deben colaborar en la medida de sus posibilidades en los proyectos pastorales que emprende la iglesia particular. Por otro lado, la capacidad de acogida de la pluriformidad eclesial que constituyen los movimientos eclesiales es un aspecto fundamental de la catolicidad de la Iglesia particular. La pluriformidad de ministerios, carismas y formas de vida no lesionan la unidad de la Iglesia particular, sino que, por el contrario, la enriquecen.

Tratando sobre la inserción de los movimientos eclesiales en las Iglesias particulares, Juan Pablo II escribe en la encíclica Redemptoris Missio (7 de diciembre de 1990):

4 Juan Pablo II (1994) utiliza expresiones como "espiritualidad de comunión", "hacer de la Iglesia la casa y la escuela de la comunión" (n.o 43). 
Recuerdo, como novedad surgida recientemente en no pocas Iglesias, el gran desarrollo de los "movimientos eclesiales", dotados de dinamismo misionero. Cuando se integran con humildad en la vida de las Iglesias locales y son acogidos por Obispos y sacerdotes en las estructuras diocesanas y parroquiales, los movimientos representan un verdadero don de Dios para la nueva evangelización y para la actividad misionera propiamente dicha. Por tanto, recomiendo difundirlos y valerse de ellos para dar un nuevo vigor, sobre todo entre los jóvenes, a la vida cristiana y a la evangelización, con una visión pluralista de los modos de asociarse y expresarse. (n. ${ }^{\circ} 72$ )

Esta humildad en la inserción presenta varios aspectos como la unión con el obispo diocesano, el aprecio sincero hacia los demás movimientos y realidades eclesiales presentes en la Iglesia particular, el espíritu de servicio y de sana colaboración con los demás fieles, etc.

Los movimientos eclesiales están particularmente vinculados al ministerio petrino, a los cuales los caracteriza el amor a la Iglesia y una unión afectiva y efectiva con el Romano Pontífice. Un gran número ha obtenido el reconocimiento de la Sede Apostólica. Sin embargo, esto no significa que sean realidades eclesiales dependientes solo del Obispo de Roma y, por tanto, exentas de la autoridad de los ordinarios diocesanos. Conviene considerar que los miembros de los movimientos eclesiales desarrollan su acción en las Iglesias particulares donde tienen su domicilio y están sujetos a las disposiciones emanadas por el obispo diocesano. Respecto de los movimientos que han obtenido el reconocimiento eclesial como asociaciones internacionales de fieles, el canon $305 \$ 2$ del Códigos de Derecho Canónico establece que están sujetas a la vigilancia del ordinario del lugar las asociaciones diocesanas y las otras, es decir, las nacionales y las internacionales, en cuanto ejercen su actividad en la diócesis. Esto significa que los obispos diocesanos han de velar para que se conserve en ellas la integridad de la fe y de las costumbres, y evitar que se introduzcan abusos en la disciplina eclesiástica.

Corresponde a la autoridad eclesiástica el deber de examinar la autenticidad de los carismas y garantizar su uso ordenado en la Iglesia. El reconocimiento de un movimiento eclesial por la Santa Sede no exime a los obispos diocesanos del discernimiento acerca de la oportunidad del inicio de la actividad de un movimiento en esa Iglesia particular. En relación con este punto, conviene precisar que el juicio global de la eclesialidad del movimiento en cuestión ha sido ya realizado en la Iglesia universal en el momento del reconocimiento del movimiento y la aprobación de sus estatutos por la Sede Apostólica. La tarea de la autoridad eclesiástica respecto de los carismas incluye también el grave deber de "no apagar el Espíritu" (1 Tes 5, 12-13).

\section{Movimientos eclesiales y conversión misionera: hacia una pastoral integrada}

En una sociedad pluralista y desvinculada como la nuestra, los movimientos eclesiales pueden ofrecer a los fieles laicos una valiosa ayuda para llevar una vida cristiana coherente con el Evangelio y para comprometerse en una intensa actividad apostólica y caritativa.

Los movimientos eclesiales poseen una pedagogía de la fe peculiar; sin embargo, no pueden ser considerados realidades eclesiales alternativas a la pastoral diocesana y parroquial. La Iglesia se realiza en la unidad de la misión que le ha sido conferida por Cristo, en una pluralidad de carismas. Los movimientos 
eclesiales no son realidades circunstanciales, para momentos de emergencia pastoral. Su aparición y su desaparición depende de la voluntad divina, no de la voluntad humana. Se puede decir, en verdad, que el Espíritu Santo sopla cuando quiere y donde quiere, y otorga los carismas que precisa la Iglesia en cada momento de la historia.

Algunos de los movimientos eclesiales nacieron precisamente después del Concilio Vaticano II. Está todavía por estudiar en profundidad la contribución de los movimientos eclesiales a la renovación de la vida de la Iglesia en los últimos cuarenta años, manifestada en conversiones, vocaciones, etc.

Los movimientos eclesiales tienen un papel particular en el desafío a los fenómenos de descristianización y en la respuesta a la demanda de religiosidad. Corresponde al obispo solicitar su colaboración en el camino pastoral diocesano y al párroco facilitar su presencia en el tejido comunitario parroquial, sin privilegios ni exclusiones. En este contexto, el obispo tiene no solo una tarea de coordinación e integración, sino de verdadera guía de la pastoral en su conjunto, llamando a todos a vivir la comunión diocesana. La diócesis y la parroquia deben facilitar la acogida de las diversas realidades eclesiales, asegurar la formación cristiana de todos y garantizar a cada movimiento eclesial un lugar adecuado en la Iglesia particular que sea respetuoso del propio carisma.

Para llevar a cabo esta misión, se precisa, en primer lugar, solicitud pastoral, es decir, el sincero interés del pastor, obispo o sacerdote, hacia estas nuevas realidades eclesiales. Conociendo a sus miembros y el carisma, se puede comprender y orientar mejor a los movimientos eclesiales. A este fin resultan oportunos tanto los encuentros personales con los responsables de los movimientos eclesiales presentes en la diócesis y la parroquia como los encuentros generales con los miembros de los movimientos (encuentros de oración, celebraciones litúrgicas, momentos de convivialidad, etc.), que ayudan a experimentar la cercanía de los pastores de la Iglesia y, a la vez, a hacer amable el ejercicio de la autoridad.

Esta solicitud pastoral se manifiesta en un acompañamiento paterno cuando el pastor se pone en actitud de servicio hacia el Pueblo de Dios que ha sido confiado a su cuidado pastoral. La Iglesia se edifica cuando el pastor y su pueblo caminan juntos, cuando los fieles sienten la cercanía de un pastor que los sirve. Se requiere también una vigilancia atenta, que ayude a los pastores a discernir todo lo que es bueno para el entero Pueblo de Dios, como escribe san Pablo (1 Ts 5, 12; 19-21), para que todos los carismas eclesiales cooperen al bien común, en su diversidad y complementariedad.

Ayudará también a este objetivo que en los seminarios y en los centros superiores de formación teológica se estudie el tema de los movimientos eclesiales en las asignaturas de Eclesiología y Teología Pastoral, para que los futuros pastores de la Iglesia puedan tener un mayor conocimiento de estas realidades eclesiales.

Termino estas reflexiones. Los movimientos eclesiales pueden seguir dando su contribución a la desconcentración de la tarea evangelizadora, que no pertenece exclusivamente al ministerio de los pastores, sino a todos los fieles bautizados. Para esta misión, se requiere un mayor aprecio de los dones carismáticos presentes en las Iglesias particulares (laicales, de vida consagrada, etc.) y la valorización de las aportaciones de los fieles laicos en el ámbito de la misión, pues, como ha escrito el papa Francisco, en la exhortación apostólica Evangelii gaudium, "son simplemente la inmensa mayoría del Pueblo de Dios" (n. $\left.{ }^{\circ} 102\right)$. 


\section{Referencias}

Álvarez de las Asturias, N. (2017). La relación entre jerarquía y carismas en la historia del derecho canónico. Revista Española De Teología, 77(1/2), 189-211.

Benedicto XVI. Vaticano II. Mensaje del Santo Padre Benedicto XVI a los participantes en el II Congreso Mundial de los Movimientos Eclesiales y de las Nuevas Comunidades. Mayo 22 de 2006. https://www.vatican.va/ content/benedict-xvi/es/messages/pont-messages/2006/documents/hf_ben-xvi_mes_20060522_ecclesialmovements.html

Catecismo de la Iglesia Católica. https://www.vatican.va/archive/catechism_sp/index_sp.html

Coda, P. (2018). I nuovi movimenti e comunità ecclesiali nella nuova tappa di evangelizzazione e nel kairós della sinodalità. En Carisma e istituzione in movimenti e comunità ecclesiali (pp. 33-44). Libreria Editrice Vaticana.

Comisión Teológica Internacional. La sinodalidad en la vida y en la misión de la Iglesia. Marzo 2 de 2018. https:// www.vatican.va/roman_curia/congregations/cfaith/cti_documents/rc_cti_20180302_sinodalita_sp.html

Congar, Y. M.-J. (1961). Aspects ecclésiologiques de la querelle entre mendiants et séculiers dans la seconde moitié du XIII e siècle et le début du xiv e. Archives d'histoire doctrinale et littéraire du moyen âge, 28, 35-151.

Congregación para la Doctrina de la Fe. Carta a los obispos de la Iglesia católica sobre algunos aspectos de la iglesia considerada como comunión. Mayo 28 de 1992. https://www.vatican.va/roman_curia/congregations/cfaith/ documents/rc_con_cfaith_doc_28051992_communionis-notio_sp.html

Congregación para la Doctrina de la Fe. Carta Iuvenescit Ecclesia a los obispos de la Iglesia católica sobre la relación entre los dones jerárquicos y carismáticos para la vida y misión de la Iglesia. Mayo 15 de 2016. https://www.vatican. va/roman_curia/congregations/cfaith/documents/rc_con_cfaith_doc_20160516_iuvenescit-ecclesia_sp.html

Delgado Galindo, M. (2013). La primavera de la Iglesia: Movimientos eclesiales, fieles laicos y nueva evangelización. Editorial de la Palabra de Dios.

Francisco. Vaticano II. Exhortación apostólica Evangelii gaudium del Santo Padre Francisco a los obispos a los presbíteros y diáconos a las personas consagradas y a los fieles laicos sobre el anuncio del Evangelio en el mundo actual. Noviembre 24 de 2013. https://www.vatican.va/content/francesco/es/apost_exhortations/ documents/papa-francesco_esortazione-ap_20131124_evangelii-gaudium.html

Francisco. Vaticano II. Discurso del Santo Padre Francisco a los participantes en el III Congreso Mundial de los movimientos eclesiales y las nuevas comunidades. Noviembre 22 2014. COMUNIDADEShttps://www. vatican.va/content/francesco/es/speeches/2014/november/documents/papa-francesco_20141122_convegnomovimenti-ecclesiali.html

Francisco. Vaticano II. Exhortación apostólica Gaudete et exsultate del Santo Padre Francisco sobre el llamado a la santidad en el mundo actual. Marzo 19 de 2018. https://www.vatican.va/content/francesco/es/apost_ exhortations/documents/papa-francesco_esortazione-ap_20180319_gaudete-et-exsultate.html

Juan Pablo II. Vaticano II. Exhortación apostólica Post-sinodal christifideles laici de Su Santidad Juan Pablo II sobre vocación y misión de los laicos en la Iglesia y en el mundo. Diciembre 30 de 1988. https://www.vatican. va/content/john-paul-ii/es/apost_exhortations/documents/hf_jp-ii_exh_30121988_christifideles-laici.html

Juan Pablo II. Vaticano II. Carta apostólica Tertio millennio adveniente del Sumo Pontífice Juan Pablo II al episcopado al clero y a los fieles como preparación del jubileo del año 2000. Noviembre 10 de 1994. https://www. vatican.va/content/john-paul-ii/es/apost_letters/1994/documents/hf_jp-ii_apl_19941110_tertio-millennioadveniente.html 
Juan Pablo II. Vaticano II. Carta apostólica Novo millennio ineunte del Sumo Pontífice Juan Pablo II al episcopado al clero y a los fieles al concluir el gran jubileo del ańo 2000. Enero 6 de 2001.

Juan Pablo II. Vaticano II. Carta encíclica Redemptoris missio del Sumo Pontífice Juan Pablo II sobre la permanente validez del mandato misionero. Diciembre 7 de 1990. https://www.vatican.va/content/john-paul-ii/es/ encyclicals/documents/hf_jp-ii_enc_07121990_redemptoris-missio.html

Juan Pablo II. Vaticano II. Mensaje del papa Juan Pablo II a los participantes en el Congreso Mundial de los Movimientos Eclesiales. Mayo 27 de 1998.

https://www.vatican.va/content/john-paul-ii/es/speeches/1998/may/documents/hf_jp-ii_spe_19980527_movimenti. html

Pablo, Obispo de la Iglesia Católica. Octubre 28 de 1965. Decreto Christus Dominus sobre el ministerio pastoral de los obispos. Octubre 28 de 1965. https://www.vatican.va/archive/hist_councils/ii_vatican_council/documents/ vat-ii_decree_19651028_christus-dominus_sp.html

Pellitero, R. (2003). Los carismas en la reflexión contemporánea y su papel en la estructuración de la Iglesia. En J. R. Villar (ed.), Communio et Sacramentum, en el 70 cumpleaños del Prof. Dr. Pedro Rodríguez (pp. 535-551). Universidad de Navarra.

Ratzinger, J. (2013). La influencia de la controversia sobre las órdenes mendicantes en el desarrollo de la doctrina del primado universal del Papa, con especial consideración de san Buenaventura. En Obras completas VI: Comprensión de la revelación y teología de la historia de san Buenaventura. Biblioteca de Autores Cristianos.

Ratzinger, J. (2015a). Los movimientos eclesiales y su lugar teológico: Conferencia pronunciada en el I Congreso Mundial de los Movimientos Eclesiales (27 de mayo de 1998). En Obras completas VIII/1: Iglesia signo entre los pueblos. Escritos de eclesiología y ecumenismo. Biblioteca de Autores Cristianos.

Ratzinger, J. (2015b). Los movimientos, la Iglesia, el mundo: Diálogo en el seminario de estudio sobre el tema "Los movimientos eclesiales en la solicitud pastoral de los Obispos" (16 de junio de 1999). En Obras completas VIII/1: Iglesia signo entre los pueblos. Escritos de eclesiología y ecumenismo. Biblioteca de Autores Cristianos.

Ratzinger, J. (2015c). La eclesiología de la constitución Lumen gentium: Conferencia pronunciada en el Congreso internacional sobre la aplicación del Concilio Vaticano II, organizado por el Comité para el Gran Jubileo del ańo 2000 (27 de febrero de 2000). En Obras completas VIII/1: Iglesia signo entre los pueblos. Escritos de eclesiología y ecumenismo. Biblioteca de Autores Cristianos.

Real Academia Española. (2014). Movimiento. En Diccionario de la lengua española (23. a ed.). https://dle.rae.es/ movimiento

Sínodo de los Obispos, Segunda Asamblea general extraordinaria, Relación final Ecclesia sub verbo Dei mysteria Christi celebrans pro salute mundi (7 de diciembre de 1985), II, B, a, 4: Ench. Vat. 9, 1797.

Viana, A. (2002). Derecho canónico territorial: Historia y doctrina del territorio diocesano. Navarra Gráfica Ediciones. https://dadun.unav.edu/handle/10171/5586 